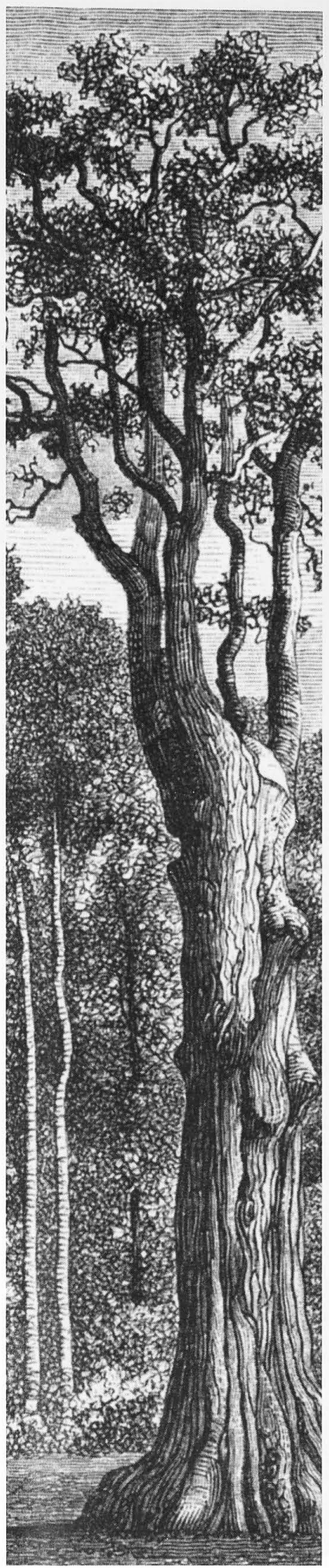

\title{
Carlos Rafael Vázquez Yanes
}

\section{(1945-1999)}

C arlos nació en Maracaibo, Venezuela el 23 de agosto de 1945 y fue mexicano de corazón a partir de 1955. Estudió la licenciatura, maestría y doctorado en Biología en la Universidad Nacional Autónoma de México, recibió varios reconocimientos nacionales e internacionales, impartió innumerables cursos en la UNAM y en la UAM, produjo aproximadamente 60 artículos de investigación (la mayoría en revistas de circulación internacional), editó dos libros científicos y escribió 26 capítulos de libros, numerosos artículos de divulgación científica, cuatro libros de divulgación científica, dirigió muchas tesis de licenciatura y posgrado. Su artículo "The tropical rain forest: a nonrenewable resource" escrito por A. Gómez-Pompa, C. Vázquez-Yanes y S. Guevara en la revista Science de 1972, es el artículo más citado en la historia de la ecología latinoamericana.

Lo más importante de la vida del Dr. Vázquez Yanes fue su sencillez, su capacidad para imaginar y para combinar diversas características tanto en su vida personal como académica. Abordó con sencilla elegancia el estudio de la ecofisiología de las especies tropicales, un campo al que no sólo impulsó en México, sino en el mundo. Investigadores de la talla del Dr. Ernesto Medina (Venezuela), Carol y Jerry Baskin (USA) y Harry Smith (Gran Bretaña), entre otros reconocen en él a un científico vanguardista, que marcó un parteaguas en el estudio de la regeneración de las selvas tropicales. En los últimos años Carlos se esforzó en ligar los conocimientos adquiridos después de muchos años de trabajar ciencia básica en los trópicos, con una nueva línea de investigación que nos permitiera abordar con mayor sustento la restauración y la reforestación con especies leñosas nativas.

Propuso continuar el desarrollo de las siguientes líneas de investigación:

- Conservación del germoplasma, tanto de especies ortodoxas como de especies recalcitrantes, y su relación con la recuperación y conservación de las comunidades vegetales.

- Realizar estudios de propagación vegetativa de las especies nativas de diferentes tipos de comunidades vegetales sin poner en riesgo la variabilidad genética.

- Estudiar los cambios fisiológicos que sufren las semillas de las especies cultivadas durante el proceso de domesticación.

- Utilizar las técnicas utilizadas por los agrónomos para producir semillas que dan lugar a plantas más vigorosas y más resistentes a condiciones extremas con fines de reforestación.

- Continuar con la recopilación de la información de especies silvestres útiles para considerar este aspecto en los programas de reforestación. 


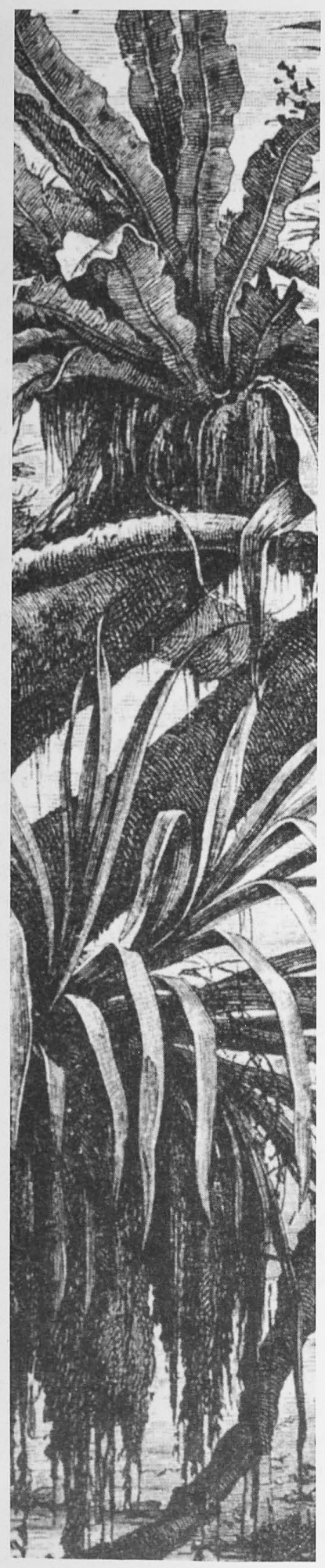

- Establecer los vínculos con biólogos que están realizando estudios de genética y con químicos para entender con mayor profundidad el papel que juega la interacción entre los mecanismos de resistencia, la genética y el ambiente en el establecimiento y el éxito de las plantas.

- Estudiar los procesos de aclimatación y de aclimatización de las plantas para incrementar el éxito de los programas de reforestación.

El Dr. Vázquez también defendió la importancia de seguir apoyando los estudios sobre la flora y la fauna de nuestro país, no sólo con el objetivo de conocer su riqueza biológica sino también con propósitos prácticos. 